\title{
Flights of fancy: Fractal geometry, the Lapita dispersal and punctuated colonisation in the Pacific
}

\author{
Ian Lilley \\ ATSIS Unit, University of Queensland, Australia \\ i.lilley@uq.edu.au
}

\section{Introduction}

Atholl Anderson has long been interested in the big questions surrounding pre-European population movement in the Asia-Pacific. For the most part, though, his publications have concentrated on the initial settlement of Remote Oceania, and particularly Polynesia, rather than either the Austronesian progression through Southeast Asia or the Lapita spread through Near Oceania. In this chapter, I would like to return to his 2001 consideration of Lapita mobility, where he asked (Anderson 2001:21) whether the large-scale pattern of episodic movement he identified in Remote Oceania could be linked at a processual level with the Lapita spread through already-inhabited parts of Melanesia and preceding population movements in Asia.

I have two aims in addressing this question. The first is to begin to explore the potential of a new way of characterising and explaining the Lapita phenomenon. My focus is on a type of episodic movement known as a 'Lévy flight'. My second aim is to consider whether the patterns and processes I discuss in this connection can be meshed with Anderson's models concerning punctuated or episodic colonisation. The objective is to help test the processual links he proposes between varying patterns or cycles of mobility stretching all the way from South China to South Polynesia. I am particularly interested to know whether the presence of existing populations in northwestern Melanesia really made any difference to the process underlying the large-scale, long-term movement of people that eventually saw the colonisation of Remote Oceania, or whether there is, to put it in Anderson's words (2001:21), 'an inherent trajectory in island colonisation which is ... self-sufficient in its processes and causes and which, if all islands were the same, would display a regular pattern of binary mobility phases?'.

\section{Anderson's models}

Atholl's evolving ideas about the settlement of the Pacific are detailed in a number of recent papers (Anderson 2001, 2003a, b, 2004). His proposals are rooted in the tenets and evidence of biogeography and his personal knowledge and experience of sailing and the sea. They also 
depend on adherence to the 'short' chronology of initial settlement in Polynesia, and especially East Polynesia, which not everyone accepts (Lilley 2006:19-21). Anderson argues on these bases that human dispersal into the Pacific was episodic rather than continuous and, if not the product of random movement, then certainly resulting from much less elaborate search strategies than the complex, risk-managing approach implicit in the now-orthodox 'against, across, then down the wind' model tendered by fellow ocean-sailor Geoff Irwin (1992).

Anderson includes Near Oceania and even Southeast Asia in his 2001 paper on Lapita mobility, but that discussion and his more recent writings on the topic draw a fundamental distinction between movement patterns in Near Oceania and Remote Oceania. As many readers will know, Remote Oceania was first settled by people with cultural and biological characteristics which derive from Near Oceania and in some cases ultimately from Asia (Spriggs 1995; Green 2000). This necessarily implicates these latter regions in any comprehensive consideration of the colonisation of the remote Pacific, as Anderson's 2001 paper and passing references in his later articles make clear. However, he is plainly concerned to achieve a certain level of analytical clarity concerning colonisation processes and so although his 2001 Lapita-mobility paper treated migration and dispersal interchangeably, his later work (2003a, b, 2004) distinguishes between the two processes, taking the 'social science view that ... [the former] refers to movement between existing populations ... [while the latter applies] to all other kinds of long-distance movements that resulted in colonisation' (2003a:71-72).

Anderson (2001:16-21) takes this view because his analysis of Lapita mobility identified 'four interesting implications' of the spatial and chronological data he examined. The last and most abstract of these implications is the prospect mentioned above that there might be an 'inherent trajectory in island colonisation'. The preceding three implications that build up to this 'conjecture' are that:

1. There appears to be a 'binary-state or dual-phase process' entailed at a large scale, with 'a stable phase which is relatively sedentary' in Near Oceania 'followed by an unstable phase of high mobility' in Remote Oceania.

2. The stable and unstable phases equate with different relationships between population and resource pressure (Keegan's (1995) K- and A-type colonising modes, respectively); and

3. There were 'significantly different' settlement and social patterns between the two phases and regions, with relatively long-lived and widely-spaced villages in Near Oceania and smaller, less-formal and only short-lived settlements in Remote Oceania.

I understand Anderson's reasoning in arriving at these conclusions, which align with conventional wisdom about the influence of existing populations on Lapita settlement and movement patterns (despite a recently reported date of $3100 \mathrm{cal}$ BP for Lapita in Vanuatu, which if confirmed, reduces the 'stable phase' Near Oceania; Galipaud and Swete Kelly 2007). Of late, however, I have come to question this latter perspective, and to think that there might be another way of conceptualising the issue that minimises the impact of existing communities. The following discussion sketches an emerging position.

\section{Fractals and Lapita in Near Oceania}

Recent methodological developments within and beyond archaeology suggest there may be some value in exploring the application of a form of fractal geometry known as Lévy flights to the questions outlined above. Fractal geometry is the non-Euclidean geometry of complex nonlinear systems. It is a branch of chaos theory that is based on the work of Benoit Mandelbrot. Apart from a couple of forward-looking contributions by the likes of Zubrow (1985) over the 


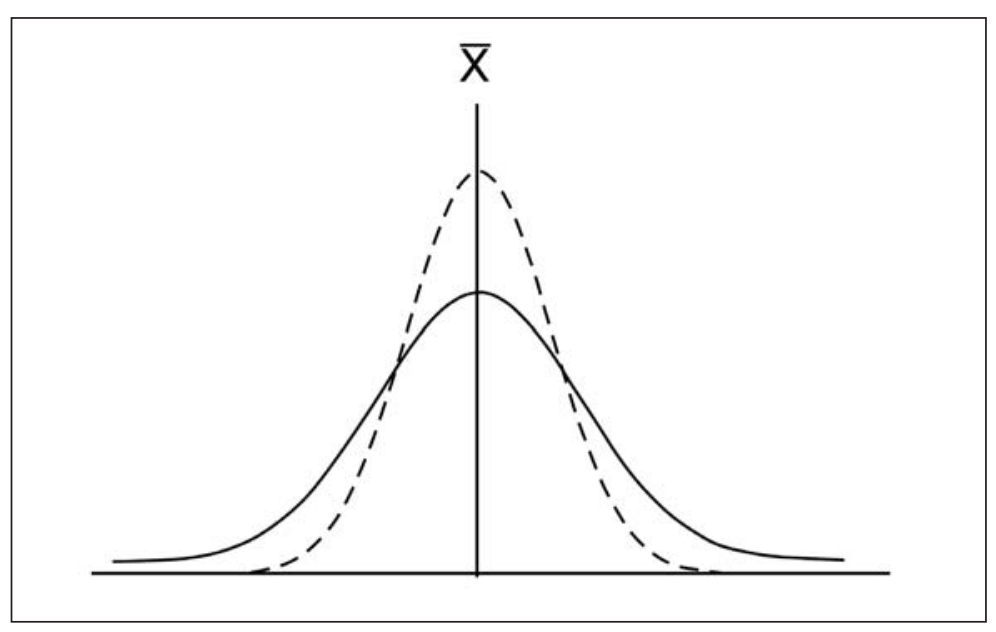

Figure 1. Gaussian or normal (broken line) and Lévy long- or heavy-tailed distributions (after Chakravarti 2004:51, Figure 1).

past two decades, fractals have only come to the attention of archaeologists over the past few years. To quote from one of the handful of papers on the matter:

Fractal geometry is the study of the form and structure of complex, rough, and irregular phenomena. In the past, many fractal patterns were mistakenly treated as if they were non-fractal. In such cases, the patterns have typically been analysed using conventional statistics, which often assume that the variation in the pattern is caused by normally distributed (Gaussian) effects. When the patterns are really fractal, classical statistical modelling yields faulty results that do not properly characterize the data. (Brown et al. 2005:40)

Lévy flights are a form of fractal geometry named after the French mathematician Paul Lévy. They characterise certain uneven patterns of diffusion. To paraphrase Brown et al. (2005, 2007; also Ravilious 2006), they are a form of random walk. In Brownian motion, the best-known kind of random walk, the sizes of the steps are normally distributed (Figure 1). Over time, this gives an even, 'wave-of-advance' dispersal pattern like Ammerman and Cavalli-Sforza's (1971; also Ackland et al. 2007) well-known model for the expansion of agriculturalists into Europe, Keegan's (1995) 'K-type pattern' of settlement in the Caribbean, and, of most direct relevance here, Irwin's (1992) 'against, across and then down the wind' model of Pacific colonisation (Figure 2 and Figure 3).

In contrast, Lévy flights exhibit step lengths with distributions characterised by 'power-law tails' (Figure 1). Essentially, this means the distributions are characterised by groups of small steps indicative of intense, localised activity that are joined by occasional very large steps that jump across large areas in which no groups of small steps occur (Figure 4). This feature causes what is called anomalous diffusion or super diffusion; it results, in other words, in extremely rapid dispersal. Because of the power-law distribution of step lengths, Lévy flights produce fractal patterns in space. This has certain implications, the most important of which here is that they are 'scale invariant' and so exhibit what are called 'self-similar' patterns at all scales (i.e. local, regional, global).

Why is any of this relevant to the Lapita dispersal? I think it is pertinent to our consideration of three factors:

- the speed of the Lapita spread,

- its unevenness or patchiness at both regional and subregional scales, and 
- the way it might link through scale-invariance with Anderson's models concerning the punctuated colonisation of the remote Pacific.

I will discuss the last point in a separate section towards the end of the chapter. Regarding speed, Anderson (2001:16) has pointed out that the Norse colonisation of the North Atlantic and the colonisation of East Polynesia were 'rather faster' than the Lapita dispersal. Yet as he concedes immediately after making that observation, it is still generally agreed that the Lapita spread was very rapid, archaeologically speaking.

By regional patchiness I mean the large gaps in the distribution of classic Lapita on the New Guinea mainland and in the Solomons. Anderson (2001:16) puts it well:

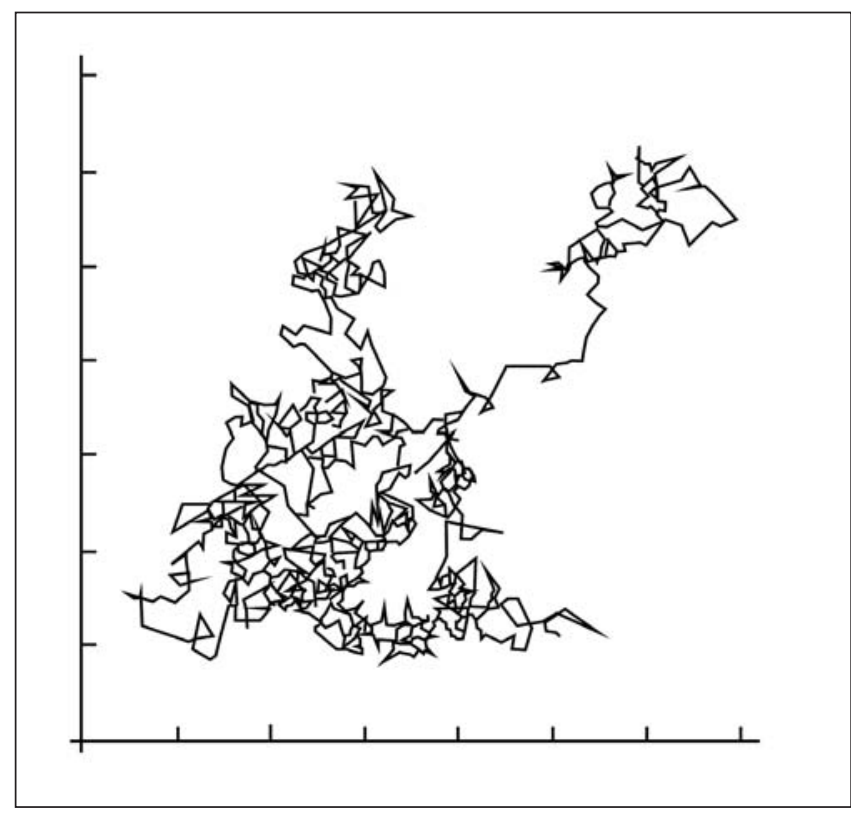

Figure 2. An example of 1000 steps of an approximate Brownian motion in two dimensions (after'Lévy flight' Figure 1, Wikipedia electronic document http://en.wikipedia.org/wiki/ L\%C3\%A9vy_flight last accessed 20 March 2008).

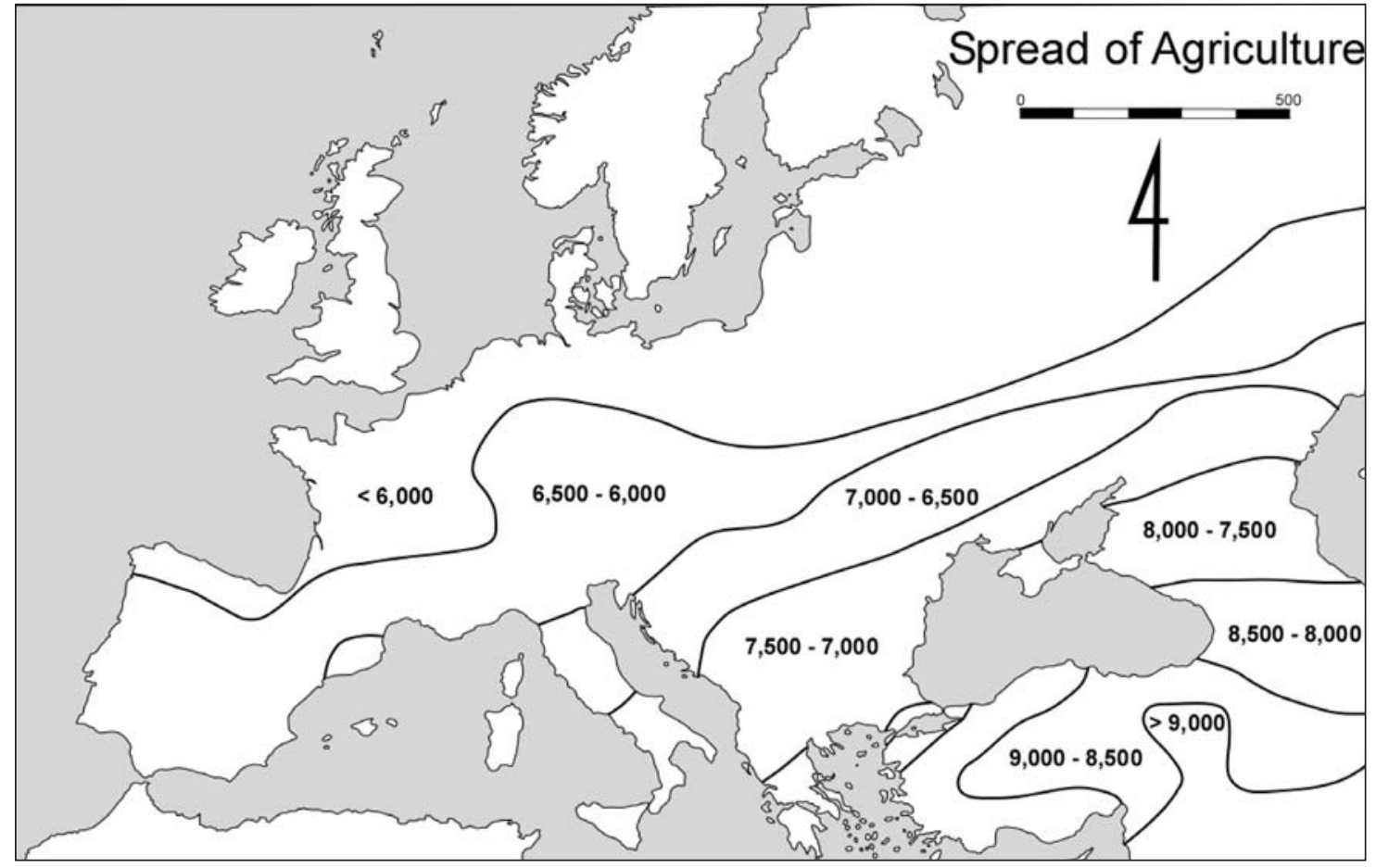

Figure 3. The wave of advance of agriculture through Europe (after Ammerman and Cavalli-Sforza 1971:685, Figure 6). 
[T] he broad pattern of current distributional data has remained much the same for more than 20 years, suggesting that it is not just on grounds of relative site recording intensity that the density of sites on the coasts of large islands is lower than on small islands throughout the Lapita range, or that mainland New Guinea, and perhaps the main Solomon Islands, are largely bereft of Lapita sites (especially early Lapita sites).

More recently, and in contrast with the views of Felgate (2007), Sheppard and Walter (2006:67-68) have made it clear that on the basis of their current research, they also think the initial Lapita dispersal bypassed the main Solomons chain:

[T] here is no evidence for early Lapita settlement in the Solomon Islands outside the record in Remote Oceania - primarily that in the Reef/Santa Cruz Islands ... Based on the archaeological, genetic and linguistic data, it seems evident that the Reef/Santa Cruz Islands were settled directly by populations from

New Britain with whom on-going relations were retained, while leapfrogging the Solomon Islands.

To anticipate discussion below, it is interesting in this context to note that people from Vanuatu may have 'jumped' all the way to Tonga in West Polynesia, leapfrogging New Caledonia and Fiji (Dickinson 2006:119). With regard to leapfrogging mainland New Guinea, Terrell (Terrell and Schechter 2007) has this year indicated that after considerable long-term effort, he and his colleagues have found only one minute piece of classic Lapita on the north coast of New Guinea to add to the original Aitape piece that has intrigued Pacific scholars for so long. I think on that basis that we can maintain that the New Guinea mainland was avoided by Lapita makers and users.

To turn to subregional patchiness, by this term I mean the unevenness of Lapita sitedistribution patterns within areas where Lapita sites are known. This is clear from the table in Anderson et al. (2001, which inadvertently excludes the KLK Lapita site on Tuam Island in Siassi; Lilley 2002). To take New Britain as an example, there are groups of substantial Lapita sites in the Arawe Islands, around Talasea, and in the Watom-Duke of Yorks area, as well as a group of Lapita sites around Kandrian yet to be examined and reported in detail, but there is very little Lapita elsewhere on New Britain or its immediate offshore islands. In some places, this might result from landscape change owing to volcanism, particularly at the western end of New Britain and along the north coast from Cape Hoskins to Rabaul. In other places, it

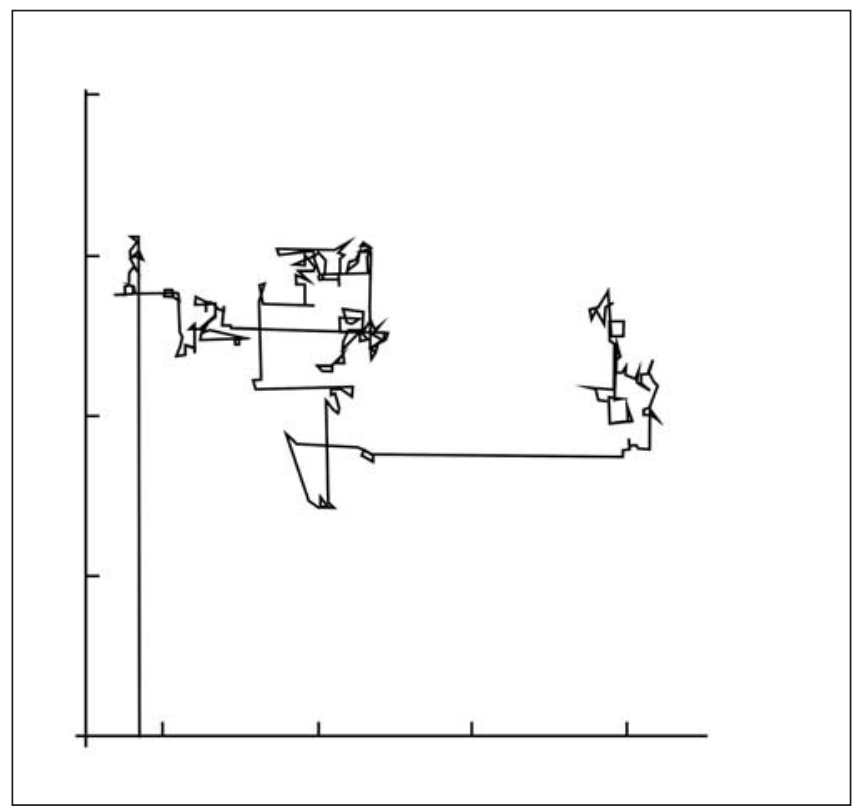

Figure 4. An example of 1000 steps of a Lévy flight in two dimensions: compare the large jumps with the Brownian pattern in Figure 2 (after 'Lévy flight' Figure 2, Wikipedia electronic document http:// en.wikipedia.org/wiki/L\%C3\%A9vy_flight last accessed 20 March). 
may result from a lack of archaeological research (the preliminary Lapita Homeland survey notwithstanding; Allen et al. 1984). However, Specht has surveyed parts of the coastline in the Cape Gloucester area (Specht 1967) and between Arawe and Kandrian (Specht 1991), and I have examined Umboi and the Siassi Islands, the Kove Islands and mainland New Britain immediately west of the Willaumez Peninsula (Lilley 1991), and the New Britain mainland around Gasmata and the offshore islands between there and Kandrian (Specht et al. 1992). I found only minor quantities of Lapita, and Specht found none around Gloucester and only one site (Kreslo) on the south coast.

Examining the distribution of Lapita sites in the New Ireland-Manus region and in Vanuatu suggests much the same sort of distribution. New Caledonia may be another matter, but even there, Lapita is far from continuously distributed. Fiji or West Polynesia definitely seem different, as suggested by Anderson's (2001:17, Table 1) demonstration that while overall Lapita site density is virtually identical in Near Oceania and Remote Oceania, and similar between Near Oceania on the one hand and Vanuatu and New Caledonia on the other, site density in Fiji-West Polynesia is twice that of Vanuatu-New Caledonia. I have yet to determine what, if anything, this difference might mean for the present modelling exercise.

For some years, numbers of Pacific researchers have been referring to Anthony's (1990) classic paper on migration in archaeology to 'explain' the rapid, leapfrogging dispersal of Lapita at the regional scale, though not, as far as I am aware, at the subregional scale considered immediately above. As Spriggs (1997:105) reminds us, Anthony noted that 'the archaeological signature of leapfrogging 'should resemble 'islands' of settlement in desirable or attractive locations, separated by significant expanses of unsettled, less desirable territory'. 'This,' Spriggs observed, 'is precisely the Lapita settlement pattern.' Like Spriggs and others including Anderson (e.g. 2001), I have found Anthony's work very useful (Lilley 2004). In the final analysis, however, it does not explain in any but the most general sense why the pattern of Lapita dispersal and settlement is as it is at any scale, rather than just giving us some terms in which to describe it.

This is where fractal geometry and especially Lévy flights come in. A considerable amount of work has been done by biologists relating foraging search patterns to Lévy flights. Brown et al. (2007:130; see also Hecht 2005) cite studies showing that Lévy flights:

are optimal search patterns for foragers searching for scarce targets that are randomly placed and can be visited any number of times ... It has been proposed that animal and insect foragers may perform Lévy flights because the probability of returning to a previously visited site is lower than for Brownian walks. Consequently, the number of newly visited sites is higher for Lévy flight searchers.

These sorts of findings led Brown and colleagues (2007) to analyse foraging patterns among San hunter-gatherers in southern Africa. The research found that these people use Lévy flight searches in their subsistence routines, and on that basis, operate at near-maximum search efficiency.

This is not the place to wade into the 'strandlooper' debate surrounding Lapita colonisation (e.g. Anderson 2003a:76-78; Davidson and Leach 2001; Kirch and Green 2001:121; Valentin et al. 2007), though the implications of the San research for this question should be apparent. Here, I would note instead that Brown et al. (2007) also briefly discuss human migration and cultural diffusion in this and their 2005 paper (also Ravilious 2006), referring explicitly to Anthony's work and his questioning of the conventional wave-of-advance model for the European Neolithic. In this connection, they (2007:135) note that it is not just leapfrogging per se that makes Lévy flights relevant to certain cases of human dispersal, but also the fact that 'Lévy flights can produce faster long-distance migration than Brownian motion because 
the latter will have few long jumps and many medium-length jumps, whereas the former will produce some surprisingly long leaps'.

This is what I think might have been happening in the Lapita context in Near Oceania: People were using a pattern of movement we can now identify as a Lévy-flight distribution to search effectively and efficiently for particular sets of resources, moving in rapid and sometimes very long leaps between patches. These leaps occurred at the subregional as well as the regional levels, producing the subregional and regional patchiness sketched above. I hypothesize that this 'selfsimilarity' at regional and subregional levels is a reflection of the scale-invariance characteristic of fractal patterns. In the same vein, Anderson's two-part larger pattern distinguishing Lapita mobility in Near and Remote Oceania may be a supra-regional dimension of the same scaleinvariant phenomenon. In this view, his initial 'stable ... [and] relatively sedentary' phase in Near Oceania would equate with the intense 'close-quarters' searching in a defined area, while the following 'unstable phase of high mobility' in Remote Oceania would equate at this scale with the Lévy 'leap' that resulted in the leapfrogging evident at regional and subregional scales. In short, it can be argued that the same two-part pattern applies to the Lapita dispersal in its entirety and at all scales of analysis.

\section{Larger patterns}

Interestingly, Anderson notes that there are also pauses and 'leaps' (if not leapfrogging) within Polynesia as well. On this basis, he (2001:21) asks whether the large-scale Lapita and Polynesian pulses he identifies might not be part of 'a progression of cyclic variation in mobility'. He (Anderson 2001:21) painted the scenario in this way:

Looking back ... [along the entire] Austronesian expansion we see stable settlement in New Zealand preceded by rapid expansion into the outlying archipelagos, preceded by several hundred years of settlement stability in East Polynesia that had followed, in turn, a phase of rapid and far-reaching migration ... Before that we had a long period of settlement stability in West Polynesia, preceded by the Lapita expansion and that in turn, perhaps, by an earlier cycle of expansion from the South China region.

Plainly, if my hypotheses are credible, there should be subregional pulses within the archipelagos of Polynesia (and indeed East and Southeast Asia and perhaps western Micronesia) of the same sort as those I have highlighted in Near Oceania. Considering this possibility in detail is beyond the scope of the present exploratory exercise, and I have not searched for any descriptions in the Polynesian literature of subregional movement that approximates a Lévy flight distribution. It should be borne in mind, though, that even if there are no such descriptions to be found, the quote from Brown et al. (2007) early in the chapter makes it clear that patterns that are actually fractal can be mistaken for Gaussian wave-of-advance distributions. The question thus remains open to empirical (re-)investigation. The same applies to East and Southeast Asia.

This is not to say that such analysis will be straightforward. Recent detailed research by Ackland et al. (2007:8716) on wave-of-advance models explicitly considers the question of leapfrogging in the early European Neolithic, 'in which small isolated enclaves of farming were formed by small-scale, long-distance migration'. They found that 'the same distribution can be produced' with a minor variation in some basic demographic parameters of the wave-of-advance scenario and 'enhanced migration rates along major rivers'. The researchers point out that there are other instances, including the settlement of Crete by $8000 \mathrm{BP}$, in which 'water-borne travel' produces long-distance leaps within an overall wave-of-advance pattern. This suggests that travelling by water, indeed, dispersing through an island world such as the Indo-Pacific, might 
produce a pattern of colonisation that appears to be a Lévy-flight distribution but in fact is still explicable as a Gaussian wave-of-advance.

This crucial point is a matter for empirical testing, to determine which dispersal model best fits the Pacific data. Of more interest to me at this tentative exploratory stage is not just that Lévy-flight research may give us a new label for particular distribution patterns, or even that it gives us the statistical tools to characterise them mathematically. Rather, as Brown and his colleagues put it (2005:67), Lévy-flight geometry also gives us the theory to 'understand the cultural dynamics that produced the patterns'. In other words, it has the potential to help us understand what might underlie the 'inherent trajectory of island colonisation' that Anderson has identified and I have discussed further in this paper.

Remember that fractal geometry is the geometry of complex non-linear systems. Nonlinear dynamics of various different kinds can generate fractal patterns. Two important sorts of non-linear systems are especially well known for generating fractal patterns: chaotic systems and self-organised systems. A system is chaotic if endpoints of trajectories of change that have very similar initial conditions diverge substantially. This basic characteristic of chaos only occurs in strongly non-linear systems, and on reflection, seems unlikely to apply to Lapita and even post-Lapita change, given the readily discernible similarities among Lapita and post-Lapita societies (Kirch 1997; Spriggs 1997), interpretations like those of Bedford and Clark (2001) notwithstanding (see also Spriggs 2003).

'Self-organised criticality' underpins another sort of complex non-linear system. Such systems evolve without external interference and trend towards the temporarily stable state of 'criticality'. The classic exemplar of this phenomenon is a pile of sand to which more sand is added one grain at a time. The slope of the pile will ultimately reach a critical state, its 'angle of repose', after which the addition of even one more grain of sand causes an 'avalanche'. This radical shift in system state is the same as the long jump in a Lévy flight, and conceptually is not dissimilar to the sudden shifts in evolutionary trajectories described by both punctuated equilibrium and catastrophe theory. Dramatic change can periodically result from even a minor perturbation if it prompts an avalanche that ramifies all the way through the interconnected elements of a system in a chain reaction. This is the proverbial 'butterfly effect' of chaos theory. Avalanches allow the system to evolve back to a critical state, where the renewed addition of more sand will eventually cause more avalanches. In other words, the system evolves back to marginal stability following perturbation, only to be 'reset' for another avalanche.

Brown et al. (2005:69) note that the concept of self-organised criticality has been applied to various human social systems, particularly war and politics. Archaeologically, Bentley and Maschner (2001) have applied the idea to stylistic change in ceramics. This idea seems likely to repay application to questions to hand here. It may help explain how, when and why population 'jumps' occurred, prompted by variations in resource distribution/ecological pressure and/or sociopolitical perturbations such as internecine rivalries (e.g. Anderson 2003b:181-184, 2004). Analysis of the sort undertaken by Bentley and Maschner (2001) may also help identify and explain patterns of ceramic and perhaps other cultural change that would illuminate aspects of the Lapita and wider Austronesian dispersal through the Asia-Pacific. While they (Bentley and Maschner 2001:61) note that 'the process of 'lumping' archaeological types and the incompleteness of the archaeological record may make self-organised criticality difficult to test with strictly archaeological data', they also argue that 'Artifact styles have irreversible histories, and with enough data, their descent should be traceable in a hierarchical pattern - patterns that can be seen as avalanches of causally-connected change' (Bentley and Maschner 2001:50).

Specialist mathematical assessment will be required to distinguish between Lévy-flight 
distributions and the Gaussian waves of advance distorted by 'water-borne travel' suggested by Ackland et al. (2007). In considering this question, we must, of course, address the vital matter of Lapita sailing technology, a constant theme in Anderson's work. This is because the maximum distance of any 'leap' (or shape of any distorted Gaussian wave) will to a large extent be a function of the sophistication of the watercraft being used. In the right conditions, a canoe with a sail can travel much further in a given period than one without. However, we already have the tools to produce the data needed for analyses like those advocated by Bentley and Maschner (2001). For ceramics, we have research of the sort behind Dickinson's (2006) demonstration that some Lapita potters took what at first glance looks very much like a Lévy flight directly from Vanuatu to Tonga, despite the presence of the large and resource-rich islands of Fiji in between. Similar combinations of fine-grained stylistic analysis and petrographic sourcing should be able to link assemblages in the ramifying or hierarchical manner described by Bentley and Maschner, ultimately allowing us to very closely map the pattern of initial Lapita dispersal from the Bismarcks through Island Melanesia and West Polynesia. Similar studies should be possible with stone and perhaps certain other non-ceramic assemblages, too, deploying high-precision sourcing of the sort recently used in Collerson and Weisler's (2007) ground-breaking study of Polynesian trade. Appropriately applied, investigations such as these will help keep research into the Lapita dispersal at the forefront of studies of human population movement as the differences between fractal and Gaussian distributions are more thoroughly examined.

\section{And the people behind the pot sherds?}

There is one obvious implication of linking the process underlying Lapita dispersal through Near Oceania to that driving the initial movement of people through Remote Oceania, and then tying both to a larger process propelling the movement of Austronesian speakers out from East and Southeast Asia. This is that it 'dehumanises' our interpretation of Pacific prehistory by eliminating agency on the part of the colonisers and by denying the impact on the Lapita phenomenon of the populations that had lived in East and Southeast Asia and Near Oceania for tens of millennia before Austronesian speakers appeared on the scene. Such an implication may be thought to conflict with received archaeological wisdom. Propositions such as Green's (2000) influential 'intrusion, integration and innovation' ('Triple-I') model, for example, and my $(1999,2004)$ diaspora hypothesis hold that the Lapita phenomenon results directly from the interaction of new and existing populations in Near Oceania. Indeed, one of the most basic characteristics of the Lapita settlement pattern in the region, namely a predilection for small offshore islands, is seen to reflect the fact that the larger islands were already occupied (e.g. Spriggs 1995:126). Lévy flight and similar sorts of processual models might even appear to ignore seemingly incontrovertible genetic evidence that intercourse between locals and settlers was biological as well as social (e.g. Oppenheimer 2003).

In fact, modelling of the sort explored above, like that investigated elsewhere by Anderson, does none of these things. It is all a matter of analytical scale, as Murray has recently reminded us (Lucas 2007:161-162). It is inconceivable to me that existing populations in Near Oceania had no influence on short-to-medium-term events and processes at a local scale. Nor is it supportable at the level of the individual and the community to characterise Austronesian settlers as mindless automatons who were simply pushed and pulled around the place by large-scale biogeographical processes. It is clear to me, though, that the agency of individual social actors and the social relationships within and between particular communities are irrelevant at the level of geographical and chronological resolution we are dealing with here. We are considering the processes of population movement entailed in the settlement of vast areas over tens of 
generations. Recalling Braudel, I would argue in this context that intermediate-scale processes such as 'introduction, integration and innovation' or diaspora formation are what emerge when global processes impact on local events and individuals and communities have to contend with the impositions of the longue durée on everyday life. When dealing with the former rather than the latter, as Anderson usually does, the importance of any difference between migration and dispersal seems moot.

\section{Acknowledgements}

Different versions of the Levy flights part of this paper were presented at conferences in Honiara (Solomon Islands) and Gotland (Sweden) before being incorporated into the present piece. I thank all those who gave me feedback on those occasions, including Atholl, even if it looks as if I didn't listen to any of you! An anonymous reviewer also added some crucial insights. My research activity and conference travel is very generously supported by Michael Williams, Director of the ATSIS Unit at the University of Queensland.

\section{References}

Ackland, G., M. Signitzer, K. Stratford and M. Cohen 2007. Cultural hitchhiking on the wave of advance of beneficial technologies. Proceedings of the National Academy of Sciences 104(21):8714-8719.

Allen, J., W. Ambrose, J. Specht and D. Yen 1984. Lapita Homeland Project: Report of the 1984 Field Season. Canberra: Australian National University.

Ammerman, A. and L. Cavalli-Sforza 1971. Measuring the rate of spread of early farming in Europe. Man NS 6(4):674-688.

Anderson, A. 2001. Mobility models of Lapita migration. In G. Clark, A. Anderson and T. Vunidilo (eds), The Archaeology of Lapita Dispersal in Oceania, pp. 15-23. Canberra: Pandanus Press.

Anderson, A. 2003a. Initial human dispersal in Remote Oceania: pattern and explanation. In C. Sand (ed), Pacific Archaeology: Assessments and Prospects, pp. 71-84. Nouméa: Département Archéologie.

Anderson, A. 2003b. Entering uncharted waters: models of initial colonization in Polynesia.

In M. Rockman and J. Steele (eds), Colonization of Unfamiliar Landscapes, pp. 169-189.

London: Routledge.

Anderson, A. 2004. It's about time. In T. Murray (ed), Archaeology from Australia, pp. 3-17. Melbourne: Australian Scholarly Publishing.

Anthony, D. 1990. Migration in archaeology: the baby and the bathwater. American Anthropologist 92:895-914.

Bedford, S. and G. Clark 2001. The rise and rise of the incised and applied relief tradition: A review and reassessment, In G. Clark, A. Anderson and T. Vunidilo (eds), The Archaeology of Lapita Dispersal in Oceania, pp. 61-74. Canberra: Pandanus Books.

Bentley, A. and H. Maschner 2001. Stylistic change as a self-organized critical phenomenon: An archaeological study in complexity. Journal of Archaeological Method and Theory 8:35-66.

Brown, C., L. Liebovitch and R. Glendon 2007. Lévy flights in Dobe Ju/'hoansi foraging patterns. Human Ecology 35:129-138.

Brown, C., W. Witschey and L. Liebovitch 2005. The broken past: Fractals in archaeology. Journal of Archaeological Method and Theory 12:37-78.

Burley, D. and W. Dickinson 2001. Origin and significance of a founding settlement in Oceania. Proceedings of the National Academy of Sciences 98(20):11829-11831. 
Collerson, K. and M. Weisler 2007. Stone adze compositions and the extent of ancient Polynesian voyaging and trade. Science 317:1907-1911.

Davidson, J. and F. Leach 2001. The strandlooper concept and economic naivety. In G. Clark, A. Anderson and T. Vunidilo (eds), The Archaeology of Lapita Dispersal in Oceania, pp. 115-123. Canberra: Pandanus Books..

Dickinson, W.R. 2006. Temper sands in prehistoric Oceanian pottery: Geotectonics, sedimentology, petrography, provenance. The Geological Society of America. Special Paper 406.

Felgate, M. 2007. Leap-frogging or Limping? Recent evidence from the Lapita littoral fringe, New Georgia, Solomon Islands. In S. Bedford, C. Sand and S.P. Connaughton (eds), Oceanic Explorations: Lapita and Western Pacific settlement, pp. 123-140. Terra Australis 26. ANU E Press, Australian National University.

Galipaud, J-C. and M.C. Swete Kelley 2007. Makue (Aore Island, Santo, Vanuatu): A new Lapita site in the ambit of New Britain obsidian. In S. Bedford, C. Sand and S.P. Connaughton (eds), Oceanic Explorations: Lapita and Western Pacific settlement, pp. 151-162. Terra Australis 26. ANU E Press, Australian National University.

Green, R. 2000. Lapita and the cultural model for intrusion, integration and innovation. In A. Anderson and T. Murray (eds), Australian Archaeologist: Collected papers in honour of Jim Allen, pp. 372-392. Canberra, Coombs: Academic Publishing.

Hecht, J. 2005. Animals forage with near-perfect efficiency. New Scientist http://www.newscientist. com/article.ns?id=dn7419.

Irwin, G. 1992. The Prehistoric Exploration and Colonisation of the Pacific. Cambridge: Cambridge University Press.

Keegan, W. 1995. Modeling dispersal in the prehistoric West Indies. World Archaeology 26(3):400-420. Kirch, P.V. 1997. The Lapita Peoples. Oxford: Blackwell.

Kirch, P.V. and R.C. Green 2001. Hawaiki, Ancestral Polynesia. Cambridge: Cambridge University Press. Lilley, I. 1991. Lapita and post-Lapita developments in the Vitiaz Strait-West New Britain Area. Bulletin of the Indo-Pacific Prehistory Association 11:313-322.

Lilley, I. 1999. Lapita as politics. In J-C. Galipaud and I. Lilley (eds), Le Pacifique de 5000 à 2000 BP : Suppléments à l'histoire d'une colonisation, pp. 21-30. Paris: Éditions de l'Institut de Recherche pour le Développement.

Lilley, I. 2002. Lapita and Type Y pottery in the KLK site, Siassi, Papua New Guinea. In S. Bedford, D. Burley and C. Sand (eds), Fifty Years in the Field. Papers in Honour of Richard Shutler, pp. 79-90. Auckland: New Zealand Archaeological Association.

Lilley, I. 2004. Diaspora and identity in archaeology: moving beyond the Black Atlantic. In L. Meskell and R. Preucel (eds), A Companion to Social Archaeology, pp. 287-312. Oxford: Blackwell.

Lilley, I. 2006. Archaeology in Oceania: Themes and issues. In I. Lilley (ed), Archaeology of Oceania: Australia and the Pacific Islands, pp. 1-28. Oxford: Blackwell.

Lucas, G. 2007. Visions of archaeology. An interview with Tim Murray. Archaeological Dialogues 14(2):155-177.

Oppenheimer, S. 2003. Austronesian spread into Southeast Asia and Oceania: Where from and when? In C. Sand (ed), Pacific Archaeology: Assessments and Prospects, pp. 54-70. Nouméa: Département Archéologie.

Ravilious, K. 2006. Locating, locating, locating. New Scientist 192(2579):44-47.

Sheppard, P. and R. Walter 2006. A revised model of Solomon Islands culture history. Journal of the Polynesian Society 115:47-76.

Specht, J. 1967. Preliminary report on visit to Kilenge, West New Britain District, T.P.N.G. Unpublished report. Sydney, Australian Museum.

Specht, J. 1991. Kreslo: a Lapita pottery site in south-west New Britain, Papua New Guinea, In J. Allen and C. Gosden (eds), Report of the Lapita Homeland Project, pp. 189-204. Canberra: Australian National University. 
Specht, J., C. Gosden, J. Webb, W. Boyd and I. Lilley 1992. Report on archaeological research in West New Britain Province, P.N.G. January-February 1992. Unpublished report. Sydney, Australian Museum.

Spriggs, M. 1995. The Lapita Culture and Austronesian prehistory in Oceania. In P. Bellwood, J. Fox and D. Tryon (eds), The Austronesians: History and Comparative Perspective, pp. 119-142. Canberra: The Australian National University.

Spriggs, M. 1997. The Island Melanesians. Oxford: Blackwell.

Spriggs, M. 2003. Post-Lapita evolutions in Island Melanesia. In C. Sand (ed), Pacific Archaeology: Assessments and Prospects, pp. 205-212. Nouméa: Département Archéologie.

Terrell, J. and E. Schechter 2007. Deciphering the Lapita code: The Aitape ceramic sequence and late survival of the "Lapita face". Cambridge Archaeological Journal 17:59-85.

Valentin, F., E. Herrscher, H, Buckley, S. Bedford M. Spriggs and K. Neal 2007. Subsistence strategies in a Lapita community: Teouma site (Vanuatu) insights from stable isotope data. Unpublished paper delivered to the Lapita Antecedents and Successors conference, Honiara, Solomon Islands. Zubrow, E. 1985. Fractals, cultural behavior, and prehistory. American Archaeology 5(1):63-77. 